Article

\title{
Genetic Investigation of Four Beluga Sturgeon (Huso huso, L.) Broodstocks for its Reintroduction in the Po River Basin
}

\author{
Caterina M. Antognazza ${ }^{1, *(\mathbb{D})}$, Isabella Vanetti ${ }^{1}$, Vanessa De Santis ${ }^{1} \mathbb{D}$, Adriano Bellani ${ }^{2}$, Monica Di Francesco ${ }^{2}$, \\ Cesare M. Puzzi ${ }^{3}$, Andrea G. Casoni ${ }^{3}$ and Serena Zaccara ${ }^{1}$ (D)
}

1 Department of Theoretical and Applied Sciences, University of Insubria, Via H. Dunant 3, 21100 Varese, Italy; isabella.vanetti@uninsubria.it (I.V.); v.desantis1@uninsubria.it (V.D.S.); Serena.Zaccara@uninsubria.it (S.Z.)

2 Parco Lombardo del Ticino, via Isonzo, 1, 20013 Pontevecchio di Magenta, Italy; adriano.bellani1955@gmail.com (A.B.); monica.difrancesco@parcoticino.it (M.D.F.)

3 G.R.A.I.A. srl Gestione e Ricerca Ambientale Ittica Acque, Via Repubblica 1, 21020 Varano Borghi, Italy; cesare.puzzi@graia.eu (C.M.P.); andrea.casoni@graia.eu (A.G.C.)

* Correspondence: caterina.antognazza@uninsubria.it

check for updates

Citation: Antognazza, C.M.; Vanetti, I.; De Santis, V.; Bellani, A.; Di Francesco, M.; Puzzi, C.M.; Casoni, A.G.; Zaccara, S. Genetic Investigation of Four Beluga Sturgeon (Huso huso, L.) Broodstocks for its Reintroduction in the Po River Basin. Environments 2021, 8, 25. https:// doi.org/10.3390/environments 8040025

Academic Editor: Chin H. Wu

Received: 1 March 2021

Accepted: 25 March 2021

Published: 27 March 2021

Publisher's Note: MDPI stays neutral with regard to jurisdictional claims in published maps and institutional affiliations.

Copyright: (c) 2021 by the authors. Licensee MDPI, Basel, Switzerland. This article is an open access article distributed under the terms and conditions of the Creative Commons Attribution (CC BY) license (https:/ / creativecommons.org/licenses/by/ $4.0 /)$.

\begin{abstract}
The reintroduction of the extinct beluga sturgeon (Huso huso L.), an anadromous species with economic and traditional relevance, is a priority in next conservation strategies in Northern Italy. The EU-LIFE NATURA project aims to reintroduce the beluga sturgeon in the Po River basin through a captive breeding program. Critical requirements for the success of the program are river connectivity and knowledge of genetic diversity of the selected broodstocks to ensure selfsustainability of reintroduced populations. Here, the four broodstocks used for the reintroduction of beluga sturgeon have been genetically screened, genotyping 13 loci and sequencing mitochondrial DNA cytochrome $b(\mathrm{Cyt} b)$ gene and the entire mitochondrial DNA control region (D-Loop). The four broodstocks showed a medium-high level of nuclear genetic variability and the presence of two sub-populations, evidencing a total level of inbreeding coefficients able to sustain the good potential as future breeders. Mitochondrial analyses showed a genetic variability comparable to wild populations, further strengthening the positive potential of the investigated broodstock. Therefore, this study, showed how the degree of genetic diversity found within the four broodstocks used for $H$. huso reintroduction in the Po River basin could be suitable to ensure the success of the program, avoiding the inbreeding depression associated with founder effect and captive breeding.
\end{abstract}

Keywords: anadromous fish; Huso huso; microsatellite; mtDNA; river fragmentation; river management

\section{Introduction}

A major factor in the global biodiversity crisis is the loss of habitat connectivity in riverine environments that has been driven by the unprecedented expansion of anthropogenic infrastructure in the last 150 years [1]. This loss of connectivity in riverine environments impedes the upstream spawning migrations of anadromous fishes and has been a major factor in the population declines of many species [2-4]. Through fragmenting the riverine environment and preventing access to spawning grounds upstream of impassable barriers, previous ecological barriers to gene flow are eroded [5], potentially leading to greater spatial and temporal overlap in the spawning of previously divergent populations.

Sturgeons (order Acipenseriformes) represent one of the most important marine and freshwater natural resources, both scientifically and commercially. Most sturgeon species are anadromous, spending much of their life at sea and then ascending rivers for spawning. Typically, sturgeons are slow growing and mature very late in life, depending on the species it can take up to 20 years, and do not spawn every year [6]. Generally, sturgeon species have diminished in numbers, and beluga sturgeon (Huso huso L.) is currently in the most critical state due to decrease in numbers of adult individuals, leading to local extinctions $[7,8]$. Currently, the distribution of beluga sturgeon is confined to a few Eastern Europe areas: 
the Black Sea, the Azov Sea, the Caspian Sea, and their main tributaries (Danube, Don and Kuban, Volga and Ural rivers) [7,9]. Its presence in the Adriatic Sea and Po River was recorded until 60 years ago, and it is now considered extinct [10]. Even though an accurate historical population assessment is not available [11], a massive decline became evident in the catches since the early 1920s, mostly due to overfishing. The population was completely extirpated from the Adriatic Sea approximately 10 years after the impoundment of the Isola Serafini Dam (Piacenza) was built in the middle of the Po River, which acted as a major barrier for fish movement [12]. Due to the long lifecycle and anadromous status, sturgeons are very susceptible to over-exploitation, pollution, and especially to habitat fragmentation [13]; among sturgeons, beluga sturgeon is known to undertake the longest upstream migration. Consequently, dams and embankments have strongly impacted this species [14], even though river fragmentation is not the only driving cause of $H$. huso decline [13]. Beluga sturgeon is, thus, listed as critically endangered under the International Union for Conservation of Nature (IUCN) World Red Data Book [15]; it is also included in appendixes II and III of the Bern Convention (CE 1979) and in the annex V of the European Habitat Directive 92/43/CEE [16].

Due to its anadromous characteristics, river longitudinal connectivity remains a critical point for the success of beluga sturgeon reintroduction, for allowing spawning migration from the sea up to suitable spawning grounds. In the last decade, restoration interventions, which are critical for the success of the sturgeon reintroduction, were implemented along the Po River basin (Northern Italy). In 2017, the major embankment, Isola Serafini (Piacenza), was modified with the construction of a double fish pass, re-establishing river connectivity (EU-LIFE project ConFluPo, 2012-2017). In the upper part of the fish pass, a monitoring station was realized, constantly working, which allows direct observations of fish movements, migrating both upstream and downstream. Throughout this major engineered construction joined to other relevant defragmentation actions (e.g., along Ticino and Tresa River), longitudinal connectivity from Adriatic Sea up to Lake Lugano, passing through Po River, Ticino River, Lake Maggiore, and Tresa River, has been completely established, becoming a promising factor for the successful reintroduction of sturgeons [17]. Along the restored Po River basin, another LIFE NATURA project- "Enhancing Biodiversity by Restoring Source Areas for Priority and Other Species of Community Interest in Ticino Park" (Life Ticino BIOSOURCE)—has been carried out specifically with the aim to reintroduce the beluga sturgeon in the Po River basin through a captive breeding program. This strategy has been adopted for years because of increasing environmental impacts from human activity to recover endangered species and/or populations from extinction [18,19]. In general, captive breeding programs use hatcheries to maintain populations that are unable to survive in the wild, aiming to restore extirpated or endangered populations [20]. The ultimate goals of these programs focus on maintaining genetic diversity and fitness within populations, allowing self-sustaining of reintroduced populations [21]. Genetic variability offers, indeed, raw material for adaptation and this is especially important in fish reintroduction where post-stocking mortality may lead to significant losses of genetic variation $[18,20]$. Therefore, molecular characterization of the breeding stocks of future reintroduced individuals is necessary for establishing a suitable genetic diversity, imperative to enhance the ability to survive and adapt to the new environment of future generations. Accordingly, the IUCN directive for reintroductions [22], the Pan European action plan for sturgeon approved by the Bern Convention [13], the WSCS "Vienna" and "Ramsar declarations on global sturgeon conservation" [23,24], and the Italian Guidelines for the introduction of fauna species [25] indicate as a priority that reintroduced individuals are "as genetically similar as possible" to the extinct population. However, the beluga sturgeon, in Northern Italy, is exclusively reared and reproduced for caviar production by aquaculture facilities, and these individuals do not descend from the extinct Italian population [9].

In this study, brood stocks for the reintroduction program, started thanks to the EU-LIFE project, were selected from different hatchery farms descended from Eastern 
European populations. According to this, the aims of this study were to (i) establish genetic variability of the broodstocks, (ii) identify possible sub-populations, and (iii) establish their phylogeographic context. The genetic analyses then included genotyping at 13 loci and sequencing of mitochondrial DNA cytochrome b (cyt b) gene and the entire mitochondrial DNA control region (D-Loop).

\section{Materials and Methods}

\subsection{Broodstocks Description}

A total of 82 samples of $H$. huso from four brood stocks were used. Specifically, 47 individuals were young beluga sturgeon ( $\geq 2$ years old, stock S1) (bought from hatchery "Fattoria del Pesce Fantinato", Novara, Italy); 12 were fry $(0+$, stock S2) coming from a second purchase batch (bought from hatchery "Pisano Dossi", Milano, Italy); 9 individuals were purchased from Hungary, stock S3 (bought from "Neptun BT 2451", Adòszàm, Hungary) and 14 individuals were purchased from a hatchery close to Mantova, S4 (bought from hatchery "L'Avannotto S.S.", Mantova, Italy) (Supplemental Material S1). All individuals, except for the fry, were pit-tagged. Individuals from stock S3 and S4 originated from fertilized eggs (Krasnodar, Russia) and belonged to a stock intended for restocking the Sea of Azov and the Don and Kuban rivers (Russia). Out of the 47 individuals from stock S1, 42 individuals were already released in the Po River system (Ticino River) between March 2019 and May 2020, during the first effort of the reintroduction program. Specifically, 35 individuals were released at Cassolnovo (Pavia, Italy, Figure 1 site T1) and the others further downstream, at Lanca Ayala (Vigevano, Italy, Figure 1 site T2) and at San Lanfranco (Pavia, Italy) (Figure 1, Site T3). During this first effort, a total of 963 individuals, all tagged, coming from stocks S1, S3, and S4 were released (Parco Ticino and GRAIA srl, personal communication).

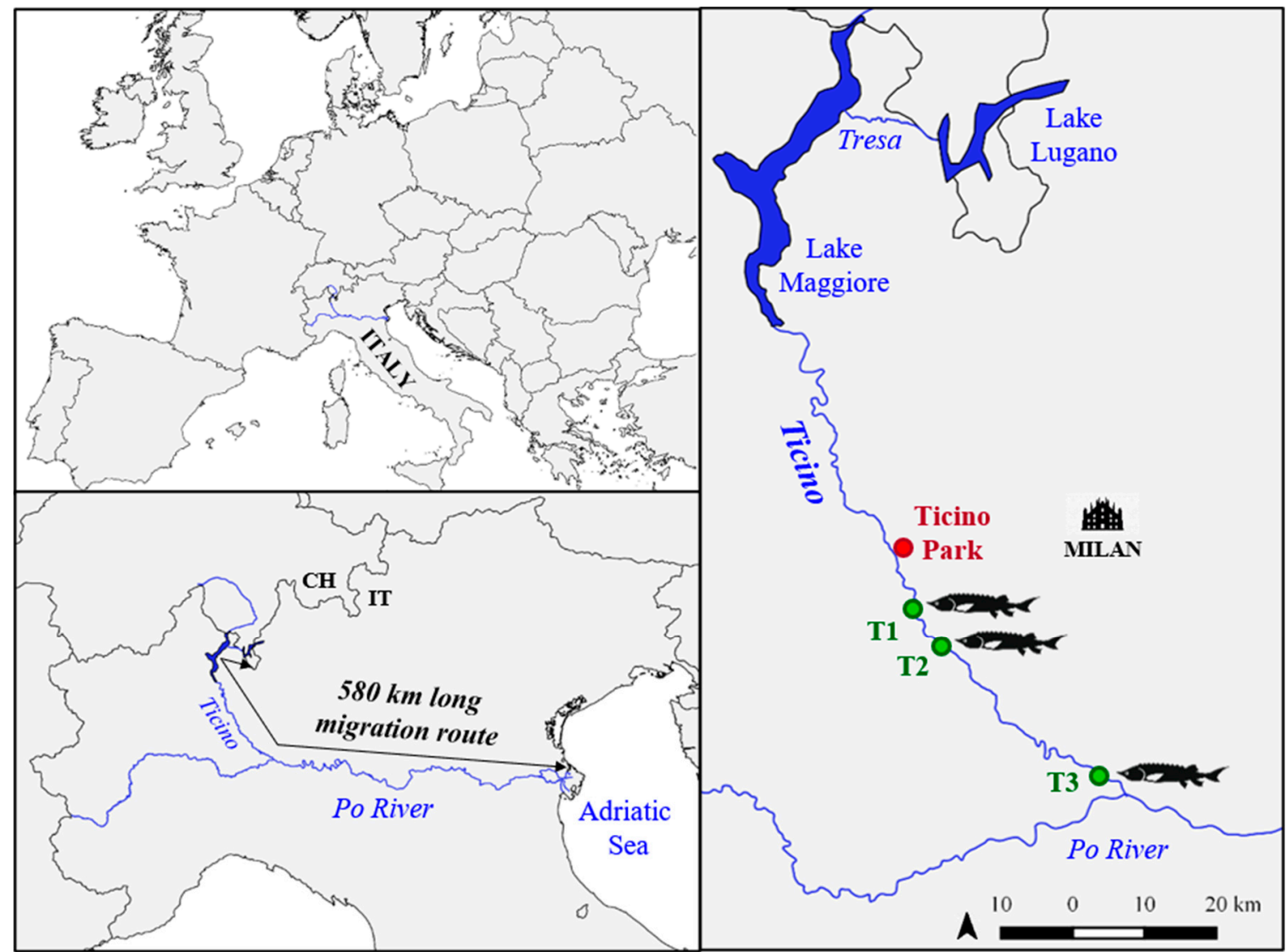

Figure 1. Map representing the Po River basin and location of Ticino Park where the broodstocks were kept before reintroduction and locations where first Huso huso individuals were released (T1 = Cassolnovo; T2 = Lanca Ayala; T3 = San Lanfranco). 


\subsection{Molecular Methods}

Extraction of genomic DNA from fin clips was completed through a proteinase K digestion followed by sodium chloride extraction and ethanol precipitation [26]. DNA was eluted in $100 \mu \mathrm{L}$ MilliQ water and stocked in freezer until next used. The genetic analyses then included (i) genotyping at 13 loci (Supplementary Material S1), sequencing of (ii) mitochondrial DNA cytochrome b (cyt b) gene, and (iii) the entire mitochondrial DNA control region (D-Loop). Each sample was genotyped at 13 loci that were previously designed for other sturgeon species (Acipenser naccarii, A. fulvescens, A. oxyrinxhus, A. gueldenstaedtii, Scaphirhynchus platorynchus) and tested on H. huso [27-31] (Supplementary Material S2). Subsets of the 13 loci were combined in four "multiplexes" for polymerase chain reaction (PCR). The primer pairs for each locus and the annealing temperatures used in each PCR multiplex can be found in Supplementary Material S2. The Type-it ${ }^{\circledR}$ Multiplex PCR Master Mix (Qiagen, Hilden, Germany) was used for all PCR according to the manufacturer's instructions in $10 \mu \mathrm{L}$ total volume reaction using about $20 \mathrm{ng}$ DNA and $0.25 \mu \mathrm{L}$ of each primer pair. The following protocol was used: after a preliminary denaturation at $95^{\circ} \mathrm{C}$ for $15 \mathrm{~min}$, each of the 30 cycles consisted of denaturation at $94{ }^{\circ} \mathrm{C}$ for $30 \mathrm{~s}$, annealing at $60{ }^{\circ} \mathrm{C}$ (at $58{ }^{\circ} \mathrm{C}$ for Mix 4) for $90 \mathrm{~s}$, and primer denaturation at $72{ }^{\circ} \mathrm{C}$ for $60 \mathrm{~s}$, and a final extension at $60{ }^{\circ} \mathrm{C}$ for $30 \mathrm{~min}$. Negative controls were included in each PCR to control for DNA contamination. Multiplexed PCR products were analyzed by Macrogen Europe B.V. (Amsterdam, The Netherlands) and allele size was measured using Peak Scanner ${ }^{\mathrm{TM}}$ Software v.1.0 (Applied Biosystem 2006, Foster City, CA, United States).

The D-Loop was amplified on a subsample of 59 individuals (Supplementary Material S1) using the primer pair ProF-PheR [32], whilst the cyt b with the primer pair Cyt-f-Cyt-r [14] was analyzed on a smaller subsample of 14 individuals (Supplementary Material S1). PCR reactions were performed using Multiplex PCR Master Mix (QIAGEN) according to the manufacturer's instructions, using about $20 \mathrm{ng}$ of DNA and $0.25 \mu \mathrm{L}$ of each primer pair in $10 \mu \mathrm{L}$ total volume reaction. The following protocol was used after a preliminary denaturation at $95^{\circ} \mathrm{C}$ for $15 \mathrm{~min}$, each of the 35 cycles consisted of denaturation at $94{ }^{\circ} \mathrm{C}$ for $30 \mathrm{~s}$, annealing at $53{ }^{\circ} \mathrm{C}$ (both primer pairs) for $90 \mathrm{~s}$, and primer denaturation at $72{ }^{\circ} \mathrm{C}$ for $90 \mathrm{~s}$, and a final extension at $72{ }^{\circ} \mathrm{C}$ for $10 \mathrm{~min}$. The PCR products were purified before sequencing using EuroSAP (EuroClone, Pero, MI, Italy) enzymatic kit, following the manufacturer's instruction. The purified products were then sent to Macrogen Europe B.V. (Amsterdam, The Netherlands) for sequencing, using only forward strand. Sequences were then manually aligned and manipulated using BioEdit v.7.0.5 [33] and Chromas Lite v.2.1 (Technelysium P. L.).

\subsection{Genetic Admixture and Substructure}

Genotyping artefacts were assessed using Microchecker v.2.2.3 [34]. Inbreeding coefficient $\left(F_{\mathrm{IS}}\right)$ [35], expected heterozygosity $\left(H_{\mathrm{E}}\right)$, observed heterozygosity $\left(H_{\mathrm{O}}\right)$, and number of alleles $\left(\mathrm{N}_{\mathrm{A}}\right)$ were calculated using GENETIX v.4.05 [36]. Genetic substructure was explored using STRUCTURE v.2.3.4 [37], varying the number of clusters (K) between 1 and 7 , using the admixture model, without using locations as prior with default parameters. Ten replicates of STRUCTURE were run per K using a burn-in of 100,000 iterations followed by 500,000 additional iterations. Each $\mathrm{K}$ was evaluated using the likelihood [37] and $\triangle \mathrm{K}$ [38] method and the outputs were visualized using STRUCTURE HARVESTER [39]. Populations pairwise $F_{\mathrm{ST}}$ values [35] and a factorial correspondence analysis (FCA), based on their multi-locus allele frequencies, were performed using GENETIX to visualize the relationship among individuals.

\subsection{Phylogenetic and Phylogeographic Relationship}

Phylogenetic analyses were carried out on the partial mitochondrial cyt b gene ( $843 \mathrm{bp}$ ). In order to establish phylogenetic and phylogeographic relationships with other sympatric sturgeon species, 45 sequences were retrieved from GenBank and added to the dataset (Supplementary Material S3). Computations of phylogenetic reconstruction of haplotypes 
were performed using two different optimality criteria: maximum likelihood (ML) and Bayesian inference (BI). The ML analysis was performed through GARLI v.1.0 [40] using K2P model of sequence evolution [41], as estimated with ModelTest v.3.7 [42]. Bayesian analysis was performed using MrBayes v.3.1.2 [43], with a Markov chain Monte Carlo algorithm (MCMC): four simultaneous and independent Markov chains from random trees were started and run for 1,000,000 generations, with the first 25,000 generations (2500 trees) discarded as the burn-in $(p<0.01)$. Phylogenetic trees were rooted using two species belonging to Poliodontidae group, a sister group of Acipenseridae: Polyodon spahula (AY510086) and Psephurus gladius (AY571339).

Genetic diversity values (i.e., haplotype, $\mathrm{H}$, and nucleotide diversity, $\pi$ ) were estimated for each group for the control region D-Loop (1023 bp) using DnaSP v.5 [44].

In the wild, three subspecies of $H$. huso are described, the differentiation of which might be due to geological history of their distribution [45]. Specifically, H. h. maeoticus is described in the Azov Sea, H. h. ponticus in the basin of the Black Sea, and H. h. caspicus is indigenous to the Caspian Sea (Supplementary Material S3). Gene genealogy was then estimated on the D-Loop extended dataset (based on mtDNA D-Loop 656 bp length) using statistical parsimony criteria in TCS v.1.21 [46] and graphically adjusted using TCS Beautifier (tcsBU) [47].

\section{Results}

\subsection{Genetic Admixture and Substructure}

Out of 13 loci, 12 resulted polymorphic with 60 as total number of alleles (Supplementary Material S4) and a mean number of 4.2, ranging between 2 for the less polymorphic loci (AoxD165 and Sp1101) and 9 for the more polymorphic ones (Anac_c31601 and Anac_c12159). Expected heterozygosity $\left(H_{\mathrm{E}}\right)$ ranged between 0.10 (Spl101) and 0.73 (Anac_c31601), whilst observed heterozygosity $\left(H_{\mathrm{O}}\right)$ ranged between 0.13 (Spl101) and 0.88 (Anac_tag71527) (Supplementary Material S5). Significant $F_{I S}$ value was reported only for Anac_c15214 locus $\left(F_{\mathrm{IS}}=0.33, p<0.05\right)$. Within the four stocks, genetic variability indexes showed level of genetic variability higher than 0.4 (i.e., $0.45<H_{\mathrm{O}}<0.60,0.42<H_{\mathrm{e}}<0.46$ ) (Table 1$)$. Inbreeding coefficient $\left(F_{\text {IS }}\right)$ was not significant only considering the four stocks as one population and for the stock S1 (Table 1). Nonetheless, all values are closed to zero, showing an acceptable inbreeding level.

Table 1. Genetic variability of the four Huso huso stocks calculated at the 13 microsatellite loci. Number of individuals analyzed, mean number of alleles $\left(\mathrm{N}_{\mathrm{A}}\right)$, observed heterozygosity $\left(H_{\mathrm{O}}\right)$, expected heterozygosity $\left(H_{\mathrm{E}}\right)$, and estimated fixation indices $\left(F_{\mathrm{IS}}\right)$ are detailed. Genetic differences $\left(F_{\mathrm{ST}}\right)$ and statistical significance (upper matrix) between the stocks.

\begin{tabular}{|c|c|c|c|c|c|c|c|c|c|c|}
\hline \multirow[b]{2}{*}{ Stock } & \multicolumn{6}{|c|}{ Genetic Variability } & \multicolumn{4}{|c|}{$F_{\text {ST }}$ Matrix } \\
\hline & $\mathbf{N}$ & $\mathbf{N}_{\mathrm{A}}$ & $H_{\mathrm{o}}$ & $H_{\mathrm{e}}$ & $F_{\text {IS }}$ & Stock & S1 & $\mathrm{S} 2$ & S3 & S4 \\
\hline S1 & 47 & 3.5 & $0.45 \pm 0.32$ & $0.42 \pm 0.26$ & -0.05 & S1 & - & 0 & 0.2 & 0 \\
\hline S2 & 12 & 2.6 & $0.57 \pm 0.41$ & $0.45 \pm 0.31$ & -0.22 & $\mathrm{~S} 2$ & 0.28 & - & 0 & 0 \\
\hline S3 & 9 & 2.6 & $0.57 \pm 0.39$ & $0.43 \pm 0.28$ & -0.26 & S3 & 0.09 & 0.21 & - & 0 \\
\hline $\mathrm{S} 4$ & 14 & 2.6 & $0.61 \pm 0.32$ & $0.46 \pm 0.22$ & -0.30 & S4 & 0.21 & 0.25 & 0.19 & - \\
\hline Tot & 82 & 4.5 & $0.50 \pm 0.26$ & $0.50 \pm 0.23$ & 0.00 & & & & & \\
\hline
\end{tabular}

Bold are significant values $p \geq 0.01$.

Calculation of $F_{\mathrm{ST}}$ revealed significant genetic differences between all stock comparisons (Table 2) ranging between 0.09 (S1 vs. S3) and 0.28 (S2 vs. S1). Factorial correspondence analysis (FCA) supported $F_{\mathrm{ST}}$ results (Figure 2a); the analysis showed a close genetic proximity between stocks S2 and S4, mainly highlighted on axis 2, whilst a closer genetic proximity between stocks S1 and S3 is highlighted on both axis 1 and axis 2 and explained by the $46.7 \%$ and $38.6 \%$ of the observed variance, respectively. All four stocks further present internal genetic variability, indeed individuals do not group closely together. (Figure 2a). These results are partly supported by Bayesian analysis (Figure 2b), which 
suggested $\mathrm{K}=2$ as the most probable number of genetic pools $(\Delta \mathrm{K}=797.805)$, grouping in one pool S1 and S3, and S2 and S4 in the second one.

Table 2. Haplotype distribution and genetic diversity based on D-Loop mtDNA sequence (1023 bp) between the four Huso huso reintroduction stocks. The number of analyzed specimen $(\mathrm{N})$ and genetic diversity (* haplotype, $\mathrm{H}$, and nucleotide, $\pi$ ) is indicated.

\begin{tabular}{|c|c|c|c|c|c|c|c|c|c|c|c|c|c|c|c|c|}
\hline Stock & $\mathbf{N}$ & Hap1 & Hap2 & Hap3 & Hap4 & Hap5 & Hap6 & Hap7 & Hap8 & Hap9 & Hap10 & Hap11 & Hap12 & Hap13 & $\mathbf{H} \pm$ s.d. & $\pi \pm$ s.d. \\
\hline S1 & 47 & 21 & 3 & 1 & 1 & 1 & & & & & & & & & $0.39 \pm 0.11$ & $0.0005 \pm 0.0002$ \\
\hline S2 & 12 & & & & & & 12 & & & & & & & & 0.00 & 0.00 \\
\hline S3 & 9 & & & & & & & 5 & 1 & & & & & & $0.33 \pm 0.21$ & $0.0003 \pm 0.0002$ \\
\hline S4 & 14 & & & & & & & 9 & & 1 & 1 & 1 & 1 & 1 & $0.60 \pm 0.15$ & $0.0011 \pm 0.0003$ \\
\hline Total & 82 & 21 & 3 & 1 & 1 & 1 & 12 & 14 & 1 & 1 & 1 & 1 & 1 & 1 & $0.78 \pm 0.03$ & $0.0079 \pm 0.0007$ \\
\hline
\end{tabular}

* GenBank Acc. Num.: MW600964-MW600976.

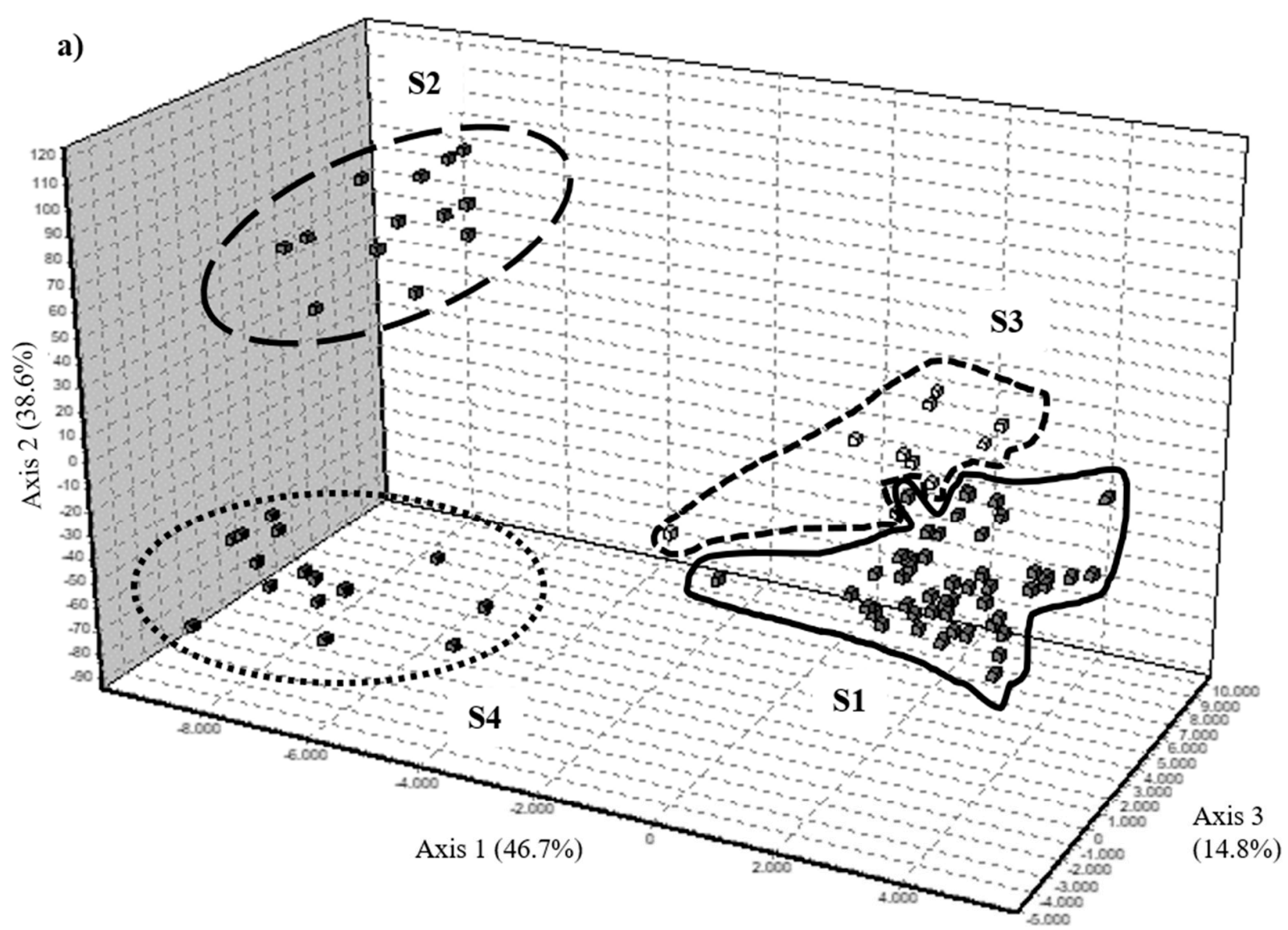

b)

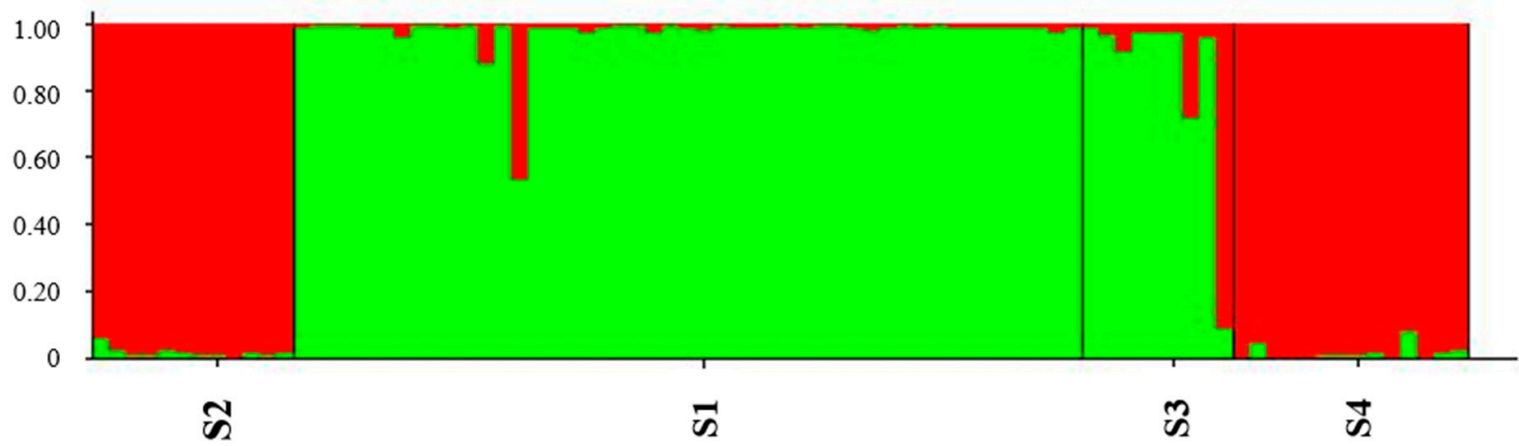

Figure 2. (a) Factorial correspondence analysis (FCA) performed on the four broodstocks and (b) STRUCTURE bar plot for $K=2$, the highest likelihood out of the seven genetic pools tested $(\Delta K=797.805)$. 


\subsection{Mitochondrial Control Region Variability}

The 1023 bp region of the $3^{\prime}$ end of the mtDNA control region (D-Loop) was aligned for 59 individuals; 13 haplotypes were identified, of which 5 were unique of stock S1 and 5 unique of S4 stock, Hap6 retrieved only in the S2 stock, and Hap8 only in S3 stock (Table 2). The only shared haplotype (Hap7) was between S3 and S4 stocks (Table 2). Seven variable nucleotide positions were detected, of which two were singletons and five were parsimony-informative sites. Haplotype diversity $(\mathrm{H})$ ranged between 0 (S2 stock) and 0.60 (S4 stock) and nucleotide diversity ( $\pi$ ) between 0 (S2 stock) and 0.001 (S4 stock) (Table 2).

The $843 \mathrm{bp}$ cyt b gene was aligned for 14 individuals and 5 haplotypes were identified. S1 and S2 stocks were represented by a unique haplotype, Huso_1 and Huso_2, respectively. S3 and S4 stock shared one haplotype, Huso_3, plus a unique haplotype, Huso_4 and Huso_5, respectively (GenBank Accession Number: MW602945-MW602949).

\subsection{Phylogenetic and Phylogeographic Relationship}

The phylogenetic analyses on extended cyt b dataset suggested that $H$. huso sequences of our stocks fell within $H$. huso cluster without any internal geographic differentiation (Figure 3). The topology of the cyt $b$ tree obtained with the Bayesian method was concordant with the one obtained by the ML method, supported by bootstrap values (Figure 3).

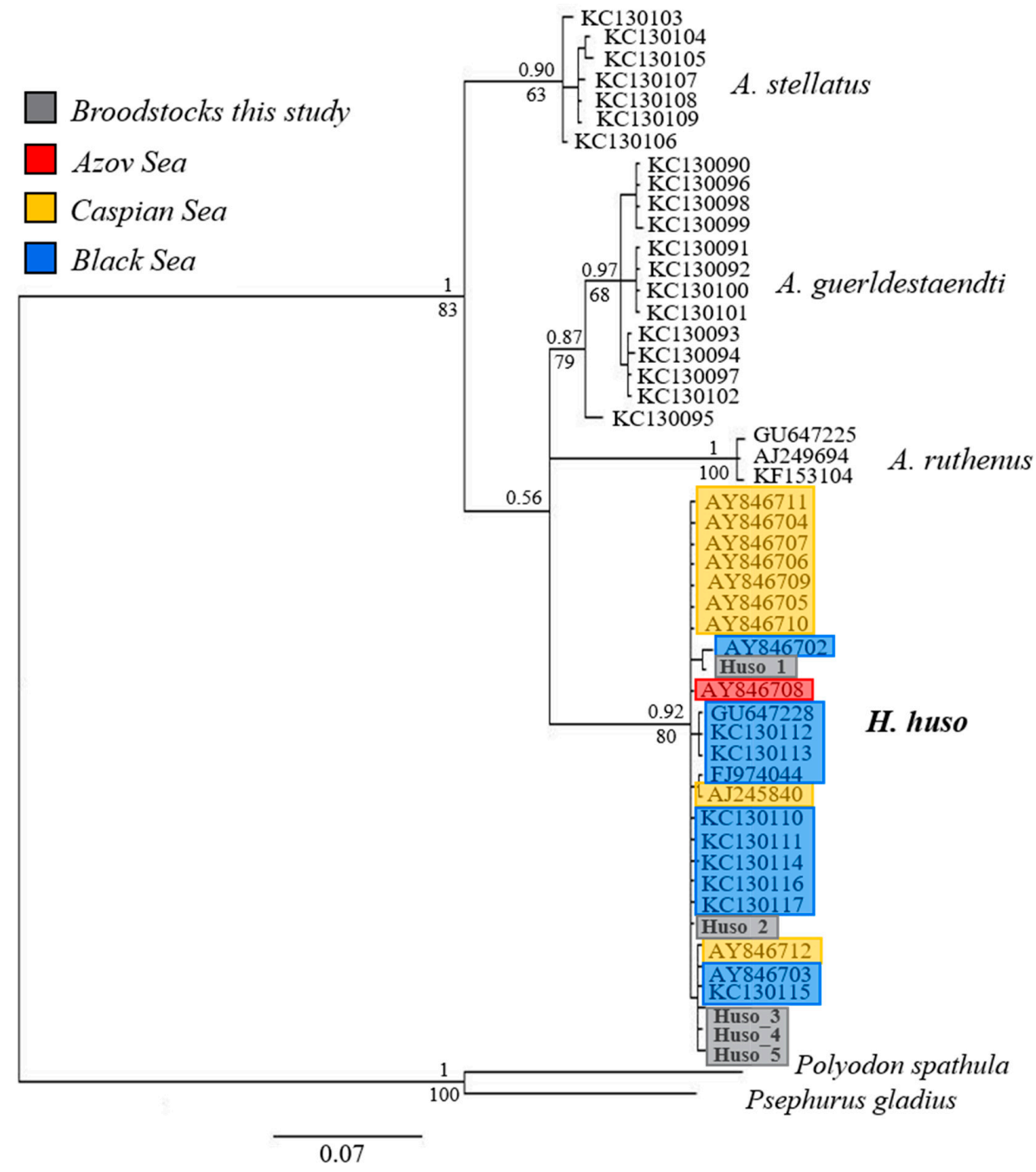

Figure 3. Phylogenetic consensus tree based on cyt b (843 bp length). Statistical support for clades was expressed as percentage of bootstrap and as posterior probability values. Trees were rooted using as outgroups Polyodon spahula (AY510086) and Psephurus gladius (AY571339). Colored labels indicate the different geographic origin of H. huso haplotypes retrieved from GenBank (cf. Table S3). 
The gene genealogy inferred on the extended D-Loop dataset (107 sequences, 656 bp) displayed an articulate connection between haplotypes and was mostly represented by hypothetical missing haplotypes (white dots) (Figure 4). Furthermore, low haplotype sharing exists among Caspian Sea, Black Sea, and Azov Sea populations, with only one haplotype shared (Pont2) (Figure 4). It is possible to observe a greater haplotypic affinity between stock S1 and subspecies H. h. ponticus (Black Sea). S2, S3, and S4 stocks are more related to H. h. caspicus (Caspian Sea).

\section{$\square$ Broodstocks this study (Huso huso)}

Azov Sea (H. h. maeoticus)

Caspian Sea (H. h. caspicus)

Black Sea (H. h. ponticus)

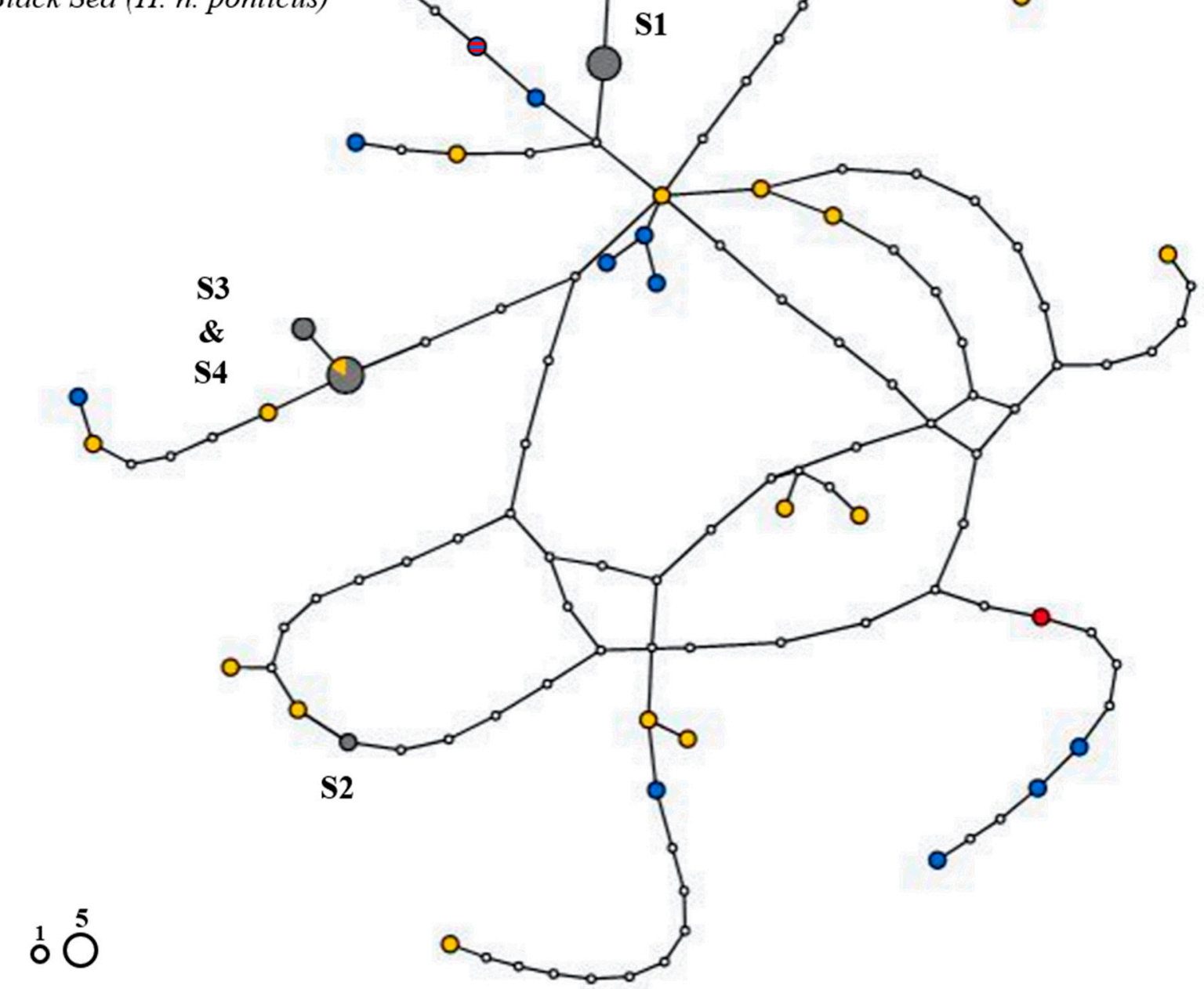

Figure 4. Minimum spanning network (MSN) based on $5^{\prime}$ end mtDNA D-Loop (656 bp length) representing the haplotypes of the four selected broodstocks and wild population of Huso huso. Different colors indicate the different geographic origin of $H$. huso haplotypes retrieved from GenBank, specifically, H. huso maeoticus from Azov Sea, H. h. caspicus from Caspian Sea, and H. h. ponticus from Black Sea and the Danube Delta (cf. Table S3). Each circle represents one haplotype, and the sizes of circles are proportional to the number of individuals sharing the same haplotype. Empty circles represent internal (missing) haplotypes.

\section{Discussion}

To be successful in terms of biological conservation, the restoration of ecological corridors needs to be coupled with plans of reintroduction and restocking of autochthonous species and, conversely, with plans of control of exotic species, along with habitat restora- 
tion measures. As river fragmentation is considered one of the major threats for long-way migrant fishes, huge plans of defragmentation have been carried out in recent years in many regions worldwide [48-50], with the main goal of promoting the return of species such as sturgeons and eels in the areas where they have been missed for many years. Specifically, in Northern Italy, the restoration of the ecological corridor from the Adriatic Sea to Lake Lugano is the most important case of river defragmentation in Italy [17]. By the construction of fish passages on Tresa, Ticino, and Po rivers, a 580-km-long migration route, precluded to the fish since the mid-1950s, was restored in recent years [17], without which any efforts to reintroduce the extinct beluga sturgeon ( H. huso) would have been wasteful.

This study was focused on the necessary preliminary genetic characterization of broodstocks then used for the reintroduction of one of the most important species of the study area from both an ecological and economical viewpoint $(H$. huso). The four broodstocks showed a medium-high level of genetic variability, considering they are not wild populations. Inbreeding coefficients $\left(F_{\mathrm{IS}}\right)$ resulted close to zero, and the Bayesian analysis also supported a low potential of inbreeding level among the four broodstocks, suggesting that these broodstocks originated from two different genetic pools (S1 and S3 vs. S2 and S4). Therefore, the presence of two possible sub-populations among the broodstocks allocated for captive breeding program, and their low inbreeding coefficients $\left(F_{\mathrm{IS}}\right)$, sustain the good potential as future breeders of the selected stocks. Genetic variability showed by the mtDNA D-Loop indicated a lower level of variability for two stocks (S1 and S2) compared to wild populations reported in literature $(\mathrm{H} \geq 0.98,[7,45])$, whilst for S3 stock and all breeders, the level of genetic variability is comparable. Nucleotide diversity is for all stocks an order of magnitude lower than that of wild population $(0.016<\pi<0.02[7,45])$. Therefore, the combination of 13 polymorphic nuclear loci with additional mtDNA information provided a positive outcome, in term of genetic variability, of the broodstocks allocated for the reintroduction program. Captive breeding programs have been developed to restore a species from the extinction [51], thus it is pivotal to ensure genetic variability, as limited as it may be, to try to reduce inbreeding depression and maintain fitness within population [52]. Numerous studies suggested regular rotation of the broodstocks during reintroduction programs to ensure that genetic diversity is maintained within the population, helping to reduce the founder effect [53].

The phylogeographic inference highlighted the absence of a clear genetic structure among the different basins that $H$. huso populate. This pattern, concordant with previous inferences on beluga $[9,54]$, as well as for two other sympatric species, such as the Russian, Acipenser gueldenstaedtii and the sterlet, A. ruthenus sturgeons [7], seems to support a signature of past reiterated admixture. Indeed, two plausible hypotheses can justify this absence: (i) the hydrogeography of the basins, thus their connections, might have changed due to the geological evolution of the area [55], although besides paleogeographic changes, human-driven translocations, which took place in the Black and Azov Sea [56], need to be taken into account, or (ii) the first reintroduction programs, acting since the late 1960s without genetic support, might not have considered the geographic origins of the broodstocks. No current data allowed us to firmly speculate on these two hypotheses [9], however, the introduction of different beluga sturgeon stocks might increase the chances of adapting to the new environment. Given the quite long generation time and anadromous lifecycle of beluga sturgeon, only future studies, no earlier than 10 years, will provide a testing scenario.

Genetics investigation within reintroduction programs are essential for monitoring many aspects, such as recruitment, genetic diversity, inbreeding, and population connectivity [57]. Continuous screening of future broodstocks is vital to keep ensuring genetic diversity and fitness within the reintroduced individuals aiming to establish a self-sustaining population $[9,20,21]$. Nonetheless, reintroduced populations need to be long-term monitored to assure the success of the program. H. huso has a long lifecycle and do not spawn every year, therefore, monitoring the reintroduced population in the following years is critical to enhancing the reintroduction program. The first release of $H$. huso individuals 
in the Po River basin was carried out between March 2019 and May 2020. A total of 963 individuals (all pit-tagged) have been released in the Ticino River close to the confluence with the Po River. The combination of genetic investigation and fish track monitoring will be important in the next years for monitoring the success of the reintroduction program. Currently, all released individuals have been intercepted at least once along the Po River, down to its delta, thanks to monitoring stations along the river course. Three individuals have been detected in the Adriatic Sea, of which one was alongside the Abruzzo (middle Italy) coast. This confirms the tendency of this species to migrate to the sea, despite the captive status of the individuals released. Thus, future monitoring will be useful to detect how the released individuals migrate back in the Po River system, ultimately for spawning.

Besides the local extinction of $H$. huso and the adverse effects on other autochthonous species, during the past decades, the river fragmentation has been associated with the proliferation of exotic species. Data on fish monitoring collected from 1993 to 2006 in the Ticino River and in the middle reach of the Po River showed the presence of a high community richness, but only 27 out of the 50 species recorded were autochthonous [58]. In general, the fish community lacked 10 species, some locally extinct while others critically endangered or almost extinct in the wild (i.e., besides H. huso, Acipenser sturio L., Petromyzon marinus L., and Lampetra fluviatilis L.) [51]. Even though the restoration of a 580-km-long migration route, from the Adriatic Sea up to the Lugano Lake, will have a primary role in migratory species, all fish communities will be impacted. The efforts in place to monitor the return of the beluga sturgeon will positively influence the monitoring of the local fish community as well on both the Po and Ticino rivers.

\section{Conclusions}

Anthropogenic barriers commonly block or obstruct migration routes of freshwater fishes, which may strongly affect populations, and even the persistence of a species. This is the case of the beluga sturgeon, which is a long-way migrant, as well as being the largest freshwater fish. Given its importance for both biodiversity conservation and the ecosystem services it provides, huge efforts have been undertaken to ensure the return of this species in the Po River basin. These efforts include construction of fish passages, habitat restoration measures, control of exotic species, and a reintroduction plan. Within this plan, the assessment of the genetic variability of the individuals to be introduced represents a fundamental action. This study showed how the degree of genetic diversity found within the four broodstocks used for $H$. huso reintroduction in the Ticino River could be suitable to ensure the success of the program, avoiding the inbreeding depression associated with founder effect and captive breeding. This work needs to be carried on in order to assure the establishment of a self-sustaining population in a hydrographic network where $H$. huso has been missed for at least 60 years.

Supplementary Materials: The following are available online at https: / www.mdpi.com/article / 10.3390/environments 8040025 /s1. Table S1: List of individuals of the four broodstocks used in this study. Name of the stock, origin of the stock, genetic identification (ID), microchip number, length and weight of adult individuals, number of microsatellite loci, fragment length of mtDNA D-Loop and Cyt b are detailed. Table S2: Microsatellite loci used in this study; name of the locus, primer sequence, repeat motif, annealing temperature, fluorescent probe and reference are listed. Table S3: References sequences retrieved from GenBank. Species, origin, GenBank accession number (code), and reference are details for both mitochondrial control region (D-Loop) and Cytochrome b gene. Table S4: Matrix of the observed allelic dimensions of each analysed locus for each individual. Genetic identification (ID), name of the stock and locus number are detailed. Table S5: Descriptive statistics of genetic diversity for all individuals and each broodstock (cf Table S1). Number of different alleles $(\mathrm{Na})$, number of effective alleles, observed heterozygosity $\left(H_{\mathrm{O}}\right)$, expected heterozygosity $\left(H_{\mathrm{E}}\right)$, fixation index $(F)$, and allele range of each locus are detailed.

Author Contributions: Conceptualization, C.M.A. and S.Z.; methodology, A.G.C. and V.D.S.; software, I.V., C.M.A., and V.D.S.; validation, formal analysis, investigation, I.V., C.M.A., and V.D.S.; resources, data curation, C.M.A.; writing-original draft preparation, C.M.A.; writing-review and 
editing, C.M.A., I.V., V.D.S., C.M.P., A.B., M.D.F., and S.Z.; visualization and supervision, S.Z. and C.M.P.; project administration, funding acquisition, S.Z., C.M.P., M.D.F., and A.B. All authors have read and agreed to the published version of the manuscript.

Funding: This research was funded by Ticino Park through LifeTicino BIOSOURCE project (LIFE15 NAT/IT/000989).

Institutional Review Board Statement: Not applicable.

Informed Consent Statement: Not applicable.

Data Availability Statement: All new haplotypes produced in this study have been deposed in GenBank under accession numbers: MW600964-MW600976 and MW602945-MW602949.

Acknowledgments: We thank Ticino Park for the support in the final development of the work. We also thank all park persons who contributed to collecting material.

Conflicts of Interest: The authors declare no conflict of interest.

\section{References}

1. Grill, G.; Lehner, B.; Lumsdon, A.E.; MacDonald, G.K.; Zarfl, C.; Reidy, L.C. An index-based framework for assessing patterns and trends in river fragmentation and flow regulation by global dams at multiple scales. Environ. Res. Lett. 2015, $10,015001$. [CrossRef]

2. Limburg, K.E.; Waldman, J.R. Dramatic Declines in North Atlantic Diadromous Fishes. BioScience 2009, 59, 955-965. [CrossRef]

3. Branco, P.; Segurado, P.; Santos, J.M.; Ferreira, M.T. Prioritizing barrier removal to improve functional connectivity of rivers. J. Appl. Ecol. 2014, 51, 1197-1206. [CrossRef]

4. Segurado, P.; Branco, P.; Avelar, A.P.; Ferreira, M.T. Historical changes in the functional connectivity of rivers based on spatial network analysis and the past occurrences of diadromous species in Portugal. Aquat. Sci. 2015, 77, 427-440. [CrossRef]

5. Seehausen, O.; Takimoto, G.; Roy, D.; Jokela, J. Speciation reversal and biodiversity dynamics with hybridization in changing environments. Mol. Ecol. 2008, 17, 30-44. [CrossRef]

6. Kottelat, M.; Freyhof, J. Handbook of European Freshwater Fishes; Publications Kottelat: Cornol, Switzerland, 2007 ; ISBN 9782839902984.

7. Dudu, A.; Georgescu, S.E.; Costache, M. Molecular analysis of phylogeographic Subspecies in three Ponto-Caspian sturgeon species. Genet. Mol. Biol. 2014, 37, 587-597. [CrossRef]

8. IUCN 2010, Versions 2010; The IUCN Red List of Threatened Species. 2010.

9. Boscari, E.; Marino, I.A.M.; Caruso, C.; Gessner, J.; Lari, M.; Mugue, N.; Barminsteva, A.; Suciu, R.; Onara, D.; Zane, L.; et al. Defining criteria for the reintroduction of locally extinct populations based on contemporary and ancient genetic diversity: The case of the Adriatic Beluga sturgeon (Huso huso). Divers. Distrib. 2021, 00, 1-12. [CrossRef]

10. Zerunian, S. Piano D'azione Generale per la Conservazione dei Pesci D'acqua Dolce Italiani; Ministero dell'ambiente e della tutela del territorio, Direzione per la protezione della natura: Rome, Italy, 2003.

11. Vecsei, P.; Suciu, R.; Peterson, D. Threatened fishes of the world: Huso huso (Linnaeus, 1758) (Acipenseridae). Environ. Biol. Fishes 2002, 65, 363-365. [CrossRef]

12. Freyhof, J.; Bergner, L.; Ford, M. Threatened Freshwater Fishes of the Mediterranean Basin Biodiversity Hotspot: Distribution, Extinction Risk and the Impact of Hydropower; EuroNatur: Radolfzell, Germany, 2020. [CrossRef]

13. Friedrich, T.; Reinarts, F.; Gessner, J. Sturgeon re-introduction in the Upper and Middle Danube River Basin. J. Appl. Ichthyol 2019, 35, 1059-1068. [CrossRef]

14. Çiftci, Y.; Eroğlu, O.; Firidin, Ş. Mitochondrial Cytochrome b Sequence Variation in Three Sturgeon Species (A. stellatus Pallas, 1771, A. gueldenstaedtii Brandt, 1833, H. huso Linnaeus, 1758) from the Black Sea Coasts of Turkey. Turk. J. Fish. Aquat. Sci. 2013, 13, 291-303. [CrossRef]

15. IUCN 2020, Versions 2020-1; The IUCN Red List of Threatened Species. 2020.

16. Council of the European Communities. Council Directive 92/43/EEC of 21 May 1992 on the conservation of natural habitats and of wild fauna and flora. Off. J. Eur. Eur. Union 1992, 206, 7-50.

17. Puzzi, C.M.; Trasforini, S.; Sartorelli, M.; Tamborini, D. Ticino River ecological corridor restoring and monitoring. Ital. J. Fresh. Icht. 2017.

18. Drauch, A.M.; Rhodes, O.E., Jr. Genetic Evaluation of the Lake Sturgeon Reintroduction Program in the Mississippi and Missouri Rivers. N. Am. J. Fish. Manag. 2007, 27, 434-442. [CrossRef]

19. Frankham, R. Genetic adaptation to captivity in species conservation programs. Mol. Ecol. 2008, 17, 325-333. [CrossRef]

20. Fraser, D.J. How well can captive breeding programs conserve biodiversity? A review of salmonids. Evol. Appl. 2008, 1, 535-586. [CrossRef]

21. Pollard, H.A.; Flagg, T.A. Guidelines for use of captive broodstocks in recovery efforts for Pacific salmon. Am. Fish. Soc. Symp. 2004, 44, 333-345.

22. Gessner, J.; Chebanov, M.; Freyhof, J. Huso huso. IUCN 2013, Version 2013.2; IUCN Red List of Threatened Species. 2010. 
23. Rosenthal, H.; Gessner, J.; Bronzi, P. VIENNA DECLARATION on Global Sturgeon Conservation; WSCS Special Publication No. 9; WSCS: Winston-Salem, NC, USA, 2018.

24. Rosenthal, H.; Pourkazemi, M. Ramsar declaration on global sturgeon conservation. J. Appl. Ichthyol. 2006, $22,5-11$.

25. Genovesi, P.; Occhipinti Ambrogi, A.; Amori, G. Linee Guida per L'immissione di Specie Faunistiche; Ministero dell'Ambiente: Rome, Italy, 2007.

26. Aljanabi, S.M.; Martinez, I. Universal and rapid salt-extraction of high-quality genomic DNA for PCR-based techniques. Nucleic Acids Res. 1997, 25, 4692-4693. [CrossRef]

27. McQuown, E.C.; Sloss, B.L.; Sheehan, R.J.; Rodzen, J.; Tranah, G.J.; May, B. Microsatellite analysis of genetic variation in sturgeon: New primer sequences for Scaphirhynchus and Acipenser. Trans. Am. Fish. Soc. 2000, 129, 1380-1388. [CrossRef]

28. Henderson-Arzapalo, A.; King, T.L. Novel microsatellite markers for Atlantic sturgeon (Acipenser oxyrinchus) population delineation and broodstock management. Mol. Ecol. Res. 2002, 2, 437-439. [CrossRef]

29. Zane, L.; Patarnello, T.; Ludwig, A.; Fontana, F.; Congiu, L. Isolation and characterization of microsatellites in the Adriatic sturgeon (Acipenser Naccarii). Mol. Ecol. Res. 2002, 2, 586-588. [CrossRef]

30. Rajkov, J.; Shao, Z.; Berrebi, P. Evolution of polyploidy and functional diploidization in sturgeons: Microsatellite analysis in 10 sturgeon species. J. Hered. 2014, 105, 521-531. [CrossRef] [PubMed]

31. Boscari, E.; Vidotto, M.; Martini, D.; Papetti, C.; Ogden, R.; Congiu, L. Microsatellites from the genome and the trascriptome of the tetraploid Adriatic sturgeon, Acipenser naccarii (Bonaparte, 1836) and cross-species applicability to the diploid beluga sturgeon, Huso huso (Linneaus, 1758). J. Appl. Ichthyol 2015, 31, 977-983. [CrossRef]

32. Congiu, L.; Pujolar, J.M.; Forlani, A.; Cenadelli, S.; Dupanloup, I.; Barbisan, F.; Galli, A.; Fontana, F. Managing Polyploidy in Ex Situ Conservation genetics: The Case of the Critically Endagered Adriatic Sturgeon (Acipenser Naccarii). PLoS ONE 2001, 6, e18249. [CrossRef] [PubMed]

33. Hall, T.A. BioEdit: A User-Friendly Biological Sequence Alignment Editor and Analysis Program for Windows 95/98/NT; Nucleic acids symposium series; Information Retrieval Ltd.: London, UK, 1999; Volume 41, pp. 95-98.

34. Van Oosterhout, C.; Hutchinson, W.F.; Willis, D.P.M.; Shipley, P. MICRO-CHECKER: A software for identifying and correcting genotyping errors in microsatellite data. Mol. Ecol. Notes 2004, 4, 63-72. [CrossRef]

35. Weir, B.S.; Cockerham, C.C. Estimating F-statistics for the analysis of population structure. Evolution 1984, 38, 1358-1370. [CrossRef] [PubMed]

36. Belkhir, K.; Borsa, P.; Chikhi, L.; Raufaste, N.; Bonhomme, F. GENETIX 4.05, Logiciel Sous Windows TM Pour la Genetique des Populations; Laboratoire Génome, Populations, Interactions: Montpellier, France, 2004.

37. Pritchard, J.K.; Stephens, M.; Donnelly, P. Inference of Population Structure Using Multilocus Genotype Data. Genetics 2000, 155, 945-959.

38. Evanno, G.; Regnaut, S.; Goudet, J. Detecting the number of clusters of individuals using the software STRUCTURE: A simulation study. Mol. Ecol. 2005, 14, 2611-2620. [CrossRef]

39. Dent, A.E.; von Holdt, B.M. STRUCTURE HARVESTER: A website and program for visualizing STRUCTURE output and implementing the Evanno method. Conserv. Genet. Resour. 2012, 4, 359-361. [CrossRef]

40. Zwickl, D.J. GARLI: Genetic Algorithm for Rapid Likelihood Inference. 2006. Available online: http:/ / www.bio.utexas.edu/ faculty/antisense/garli/Garli.html (accessed on 6 July 2020).

41. Kimura, M. A simple method for estimating evolutionary rates of base substitutions through comparative studies of nucleotide sequences. J. Mol. Evol. 1980, 16, 111-120. [CrossRef] [PubMed]

42. Posada, D.; Crandall, K.A. Modeltest: Testing the model of DNA substitution. Bioinformatics 1998, 14, 817-818. [CrossRef]

43. Ronquist, F.; Huelsenbeck, J. MRBAYES 3: Bayesian Phylogenetic inference under mixed models. Bioinformatics 2003, 19, 1572-1574. [CrossRef] [PubMed]

44. Librado, P.; Rozas, J. DnaSP: A software for comprehensive analysis of DNA polymorphism data. Bioinformatics 2009, 25, 1451-1452. [CrossRef]

45. Doukakis, P.; Birstein, V.J.E.; De Salle, R. Intraspecific structure three caviar-producing sturgeons (Acipenser gueldenstadtii, A, stellatus and Huso huso) based on mitochondrial DNA analysis. J. Appl. Ichthyol 2005, 21, 457-460. [CrossRef]

46. Clement, M.; Posada, D.; Crandall, K. TCS: A computer program to estimate gene genealogies. Mol. Ecol. 1999, 9, 1657-1659. [CrossRef]

47. Santos, A.M.; Cabezas, M.P.; Tavares, A.I.; Xavier, R.; Branco, M. tcsBU: A tool to extend TCS network layout and visualization. Bioinformatics 2016, 32, 627-628. [CrossRef] [PubMed]

48. Seliger, C.; Zeiringer, B. River Connectivity, habitat fragmentation and related restoration measures. In Riverine Ecosystem Management; Schmutz, S., Sendzimir, J., Eds.; Springer: Berlin/Heidelberg, Germany, 2018; Volume 8, pp. 171-186. [CrossRef]

49. Silva, A.T.; Lucas, M.C.; Castro-Santos, T.; Katopodis, C.; Baumgartner, L.J.; Thiem, J.D.; Cooke, S.J. The future of fish passage science, engineering, and practice. Fish Fish. 2018, 19, 340-362. [CrossRef]

50. Shao, X.; Fang, Y.; Jawitz, J.W.; Yan, J.; Cui, B. River network connectivity and fish diversity. Sci. Total Environ. 2019, 689, 21-30. [CrossRef] [PubMed]

51. Wilson, C.D. Empirical Approaches to the Conservation of Margaritifera margaritifera. Ph.D. Thesis, Queen's University, Belfast, Northern Ireland, 2010.

52. Reed, D.H.; Frankham, R. Correlation between fitness and genetic diversity. Conserv. Biol. 2003, 17, 230-237. [CrossRef] 
53. Jones, J.W.; Hallerman, E.M.; Neves, R.J. Genetic management guidelines for captive propagation of freshwater mussels (Unionoidea). J. Shellfish. Res. 2006, 25, 527-535. [CrossRef]

54. Doukakis, P.; Babcock, E.A.; Pikitch, E.K.; Sharov, A.R.; Baimukhanov, M.; Erbulekov, S.; Bokova, Y.; Nimatov, A. Management and recovery options for Ural River Beluga sturgeon. Conserv. Biol. 2010, 24, 769-777. [CrossRef] [PubMed]

55. Kotlik, P.; Markova, S.; Choleva, L.; Bogutskaya, N.G.; Ekmekcis, F.G.; Ivanova, P.P. Divergence with gene flow between Ponto-Caspian refugia in an anadromous cyprinid Rutilus Frisii revealed bymultiple gene phylogeography. Mol. Ecol. 2008, 17, 1076-1088. [CrossRef]

56. Balandina, L.G. Reproduction of beluga in the Azov basin. In Biological Bases of Sturgeon Farming; Barannikova, I.A., Berdichevsky, L.S., Eds.; Nauka: Moscow, Russian, 1983; pp. 216-223.

57. Attard, C.R.M.; Möller, L.M.; Sasaki, M.; Hammer, M.P.; Bice, C.M.; Brauer, C.J.; Carvalho, D.C.; Harris, J.O.; Beheregaray, L.B. A novel holistic framework for genetic-based captive-breeding and reintroduction programs. Conserv. Biol. 2016, 30, 1060-1069. [CrossRef] [PubMed]

58. Salmaso, F.; Quadroni, S.; Gentili, G.; Crosa, G. Thermal regime of a highly regulated Italian river (Ticino River) and implications for aquatic communities. J. Limnol. 2017, 76, 23-33. [CrossRef] 